Trans/Form/Ação, São Paulo

9/10: 1-7, 1986/87.

\title{
A CIÊNCIA DO OLHAR ATENTO
}

\author{
Lucrécia D'ALÉSSIO FERRARA*
}

RESUMO: Que é ciência? A distinção entre conhecimento cientffico e ciência como coisa viva, ciência da experiência. A dimensão cientffica das categorias de Peirce: dedução, abdução, indução. Pragmatismo peirceano. $A$ indução como elemento de ligação entre a hipótese explicativa abdutiva apenas provável e a geração de uma lei dedutiva, necessária porque normativa para hábitos de conduta.

UNITERMOS: Ciência; conhecimento cientffico; indução; dedução; abdução; experiência; lei; experimentação.

\begin{abstract}
"A ciência consiste em realmente distender o arco na direção da verdade, com atenção no olhar, com energia no braço" (3. CP. 1.235)
\end{abstract}

\section{CIÊNCIA E CONHECIMENTO CIENTÍFICO}

Onde está o prazer do conhecimento? No reconhecimento da tradição!? No domínio de uma classificação!? Na descoberta do sujeito que conhece!? Na revelação do objeto que envolve o homem!? Na união epifânica entre o ser que conhece e o objeto conhecido!? Uma simples questão: que nos ensina a ciência?

Fazer ciência não consiste em saber o que é o científico sacramentado pelo rigor de um patrimônio cultural rigorosamente definido e defendido, mas fazer ciência consiste em desenvolver uma atitude perante o objeto. Não é uma questão de saber, é, antes, uma questão de comportamento; planejar a ciência que queremos: " ciência como coisa viva e não como uma mera definição abstrata" (3. CP. 1.232). Esta é a noção básica que norteia as noções de Peirce sobre A Classificação das Ciências, uma resposta simples para questões complexas, mas que coloca para a prática desse fazer a necessidade de descobrir e de incorporar um outro valor. A lógica da linguagem de Peirce vem impregnada por esse valor e a pesquisa da linguagem supõe descobrir e/ou criar o que significa esta "coisa viva" que não pode estar, senão, na experiência da própria linguagem (Notas).

* Professora Titular do Programa de Pós-Graduação em Comunicação e Semiótica da PUC - SP e Professora Adjunta do Departamento de Projeto da FAU - USP - SP. 


\section{CIÊNCIA E DEDUÇĀO}

A pesquisa como coisa viva é produção desautorizada e nova de informação. Em que consistem desautomatização e informação nova?

A informação possui duas válvulas reguladoras: de um lado, a adaptação informacional, de outro, a inovação, a informação nova. A adaptação supõe uma redução ou tradução de informações de um repertório mais alto, para outro mais baixo, tendo em vista um aumento quantitativo de receptores da mensagem. Por outro lado, a inovação ou informação nova é, na prática, um quase signo novo, uma quase novidade, porque não é possivel operar com a informação totalmente nova, seria incompreensível. Entretanto, para ser nova, a informação deve reverter a rotina, deve ser, no mínimo, desautomatizante.

Enquanto produção de conhecimento e a partir da relação sujeito-objeto, a ciência pode partir do rigor de sistemas logicamente dedutivos, sólidos para sempre e, em tudo, corretos e verdadeiros, ou seja, sobre aquela relação sujeito-objeto constrói um superobjeto que suplanta o fato, o fenômeno existente para seduzir-se pela lógica de uma lei explicativa. A ciência converte-se numa reflexão, quando não, em comentário sobre a própria lei, sobre a teoria que a estimula na relação de conhecimento: seu estímulo não está no objeto de conhecimento, mas na lógica da lei, uma linguagem fechada, um discurso de poder a que tem acesso um grupo cada vez mais restrito de pessoas. Ciência distante da "experiência", da "coisa viva" únicas capazes de ensinar (3. CP. 5.360), ou seja, produzir uma idéia nova capaz de reverter a rotina de normas, crenças e hábitos de conduta automatizada.

Ora, produção de informação nova capaz de reverter hábitos de conduta tem como contrapartida certa "crise", certa "dúvida" (3. CP. 5.370, 371, 37.2, 373) que se projeta sobre o argumento dedutivo dando-Ihe certo indeterminismo como elemento básico da produção de conhecimento; por outro lado, é essa mesma crise que, paradoxalmente, põe em evidência a resistência da lei e o caráter inteligente e preditivo de suas generalizações.

Entretanto, para ousar correr esse risco é necessário que a dedução se aproxime da experiência, da coisa viva e sofra o impacto da abdução; a lei, a terceiridade encontra seu elemento corretivo na abdução sugerida pela experiência, na possibilidade da primeiridade e, ambas, dedução e abdução, constituem dois dos pilares do raciocínio que sustentam o pragmatismo peirceano.

\section{DEDUÇĀO E ABDUÇÃO}

Para a abdução, ciência e experiência são, mutuamente, reflexo e refração: a ciência descobre a experiência, mas esta sustenta aquela. Cabe ao raciocínio apreender o modo e a lógica dessa correlação que produz "a ciência como coisa viva", uma possível "pergunta feita à natureza“" (3. CP. 5.168), ou seja, apreensão não simplesmente descritiva, mas necessariamente interpretativa e, daí, inserida na realidade. Ciência como uma pergunta feita à natureza supõe a recuperação do universo como um conjunto de possibilidades reais, porém, parciais; supõe uma postura anti-tradicional, incerta, mais para flagrar uma possibilidade inusitada do que para acertar.

Entretanto, essa postura não é idealista ou ingenuamente anarquista pois, embora ultrapasse o rigor indiscutível das posturas dedutivas, supõe a necessidade de que um corpo de conceitos gerais seja, dinamicamente, reconceituado dentro de um amplo corpo de experiências que estabelece, entre as idéias, um novo sistema de relações. Cria-se uma fresta entre o conhecimento acumulado e teoricamente fixado e a intrigante postura que estabelece, para o cientista, uma relação interrogativa com a experiência. $A$ combinação entre os dois aspectos, dedução e abdução, nos leva à informação nova, ou seja, "asso- 
ciar o que nunca, antes, pensáramos associar" (3. CP. 5.187), aí, a descoberta de hipóteses explicativas é proporcional à capacidade de ver a realidade como um estímulo que aguça a curiosidade.

Este é o caminho da descoberta. Sem receitas, sem fórmulas, estrategicamente demolidor: cada pesquisa constrói sua determinada ciência. No edifício argumentativo da pragmática peirceana, dedução e abdução se espreitam, porque se a lei é corrigida pela experiência, a descoberta vai da surpresa do fato à esperança da lei. Reflexão e refração mútuas que nos levam da experiência para a construção de teorias e leis que orientam nossos hábitos de conduta e nossas crenças: da primeira para a terceiridade, da abdução para a dedução.

\section{DEDUÇÃO, ABDUÇÃO, INDUÇÃO}

Entre a primeira e a terceiridade, entre a abdução e a dedução está a secundidade, a indução que constitui o outro pilar daquele edifício pragmático: entre a experiência e a teoria surge a pesquisa controlada dos fatos, a etapa onde aquela pergunta feita à natureza se concretiza.

Para a ciência como coisa viva, por assim dizer, não há ciência, mas as pesquisas que se alteram, alternam, convergem e divergem de modo constante. Só entendendo a ciência como processo em crise, na eterna metamorfose do seu fazer é que questionamos a teoria, escapamos do seu dogmatismo e estamos em condições de integrar os resultados e dimensionar as conseqüências práticas da investigação.

$O$ controle indutivo experimental transforma os fatos reais em dados científicos realçando o espaço da pesquisa que permite transformar a lei em processo submisso a constantes metamorfoses, porém com capacidade pragmática de orientar nossa construção no mundo.

De certa forma, a surpresa diante do fato que leva à geração de hipóteses explicativas abdutivas na expectativa da geração de uma lei, coloca a indução como etapa necessária de controle daquela experiência e daquela hipótese; para a indução entendida tradicionalmente, o confronto entre abdução e dedução, entre fato e lei, leva a uma inversão na ordem dos fatores: em lugar de procurar fatos que comprovem uma teoria, parte deles para, experimental e controladamente, criar experimentos que possam comprovar a legitimidade de uma hipótese explicativa, até então, apenas possivel. É próprio da abdução produzir idéias, à indução cabe testar idéias e falar sobre elas, à dedução cabe generalizálas e abstratamente transformá-las em teorias ou leis. Com o acréscimo indutivo, ao lado da abdução, a pragmática peirceana tem condições de produzir, dedutivamente, uma lei capaz de orientar a conduta humana e de fazer com que a ciência encontre uma razão de ser que supere as classificações abstratas.

Entre a primeira e a terceiridade: a secundidade, o território do aqui e do agora da experiência realmente vivida em impactos de ação e reação. Território de aprendizagem fértil e constante, mundo dos fenômenos realmente existentes que só adquirem identidade e representação pela variação da própria experiência que, por sua vez, só se concretiza pela sua mediação sígnica: o índice, o sinal de um fato realmente existente.

\section{INDUÇÃO E ÍNDICE}

Essa identidade de um fenômeno pela variação entre fenômenos supõe, entre eles, um confronto, uma ação e reação comparável pela mediação de seus índices digitalizados. Logo, para a indução experimental, a descoberta desses índices é fator da própria concreção experimental dos fatos submetidos a controle. Esses indices podem ser descobertos se realmente existentes e individuais, porém os índices de um fenômeno podem 
ser uma simples referência dele, portanto, um índice degenerado.

No processo indutivo transforma-se o fato em dado científico na medida em que se identifica, no fenômeno, os sinais controláveis, ou seja, aqueles que atuam como sugestão para a consecução de uma lei. Explicando: na ciência como coisa viva, procura-se, no fenômeno, o índice que identifica uma experiência porque permite a comparação entre ela e suas correlatas e, mais do que isso, procura-se entre esses índices uma sugestão de lei, uma predição capaz de transformar uma hipótese apenas possivel em algo, não só provável como, sobretudo, necessário.

$\mathrm{Na}$ indução, procura-se nos fenômenos certos índices degenerados, ou melhor, certos indices experimentáveis de índices fenomênicos: certos índices de índices, metalingüísticos que sugerem uma investigação controlada a partir da combinação imprevista realizada entre eles - "associar o que nunca pensáramos antes associar".

Esta associação imprevista que é germe da investigação procura, nos fenômenos, as pistas, os sinais, os índices de certo modo de pesquisar, caminhos associativos: índices de indices, sinais de sinais. A partir desse ponto de vista, é possivel entender e admitir que cada investigação gera sua própria estratégia metodológica, seu próprio processo experimental: "Crer que se pode fazer progredir uma pesquisa científica aplicando-Ihe um método-tipo porque deu bons resultados em outra pesquisa da qual era conatural é uma estranha cegueira que pouco tem a ver com a ciência“(1, p. 118). A excelência do método se resolve em saber pesquisar, em saber fazer.

A identificação dos fenômenos a partir da comparação entre seus índices salienta a seleção praticada pela atenção entre as manifestações da experiência, o modo de coligação entre aquelas manifestações e a observação da ação e reação provocada pelo encontro entre experiências tensionadas. Atenção, comparação, coligação e observação são os elementos que nutrem a secundidade científica, a indução e preparam o caminho da inferência: "Os três elementos essenciais da inferência são, então coligação, observação e o juizo do que observamos entre elementos coligados conforme uma regra" (3. CP. 2.444).

\section{INDUÇĀO E REPERTÓRIO}

A indução supõe certa concessão necessária à fragmentação, não é recuperação total da experiência, mas abre nela uma fratura pela qual se introduz o juízo perceptivo e a própria historicidade do sujeito através de associações e inferências entre juízos. Por aí, o fenômeno presente, o aqui e agora da experiência se cola ao tempo passado, à história, à interpretação de um repertório.

Repertório é a memória onde indivíduos, famílias, grupos, povos ou civilizações guardam as interpretações ou juízos perceptivos: uma extensão diádica da experiência ou de sentimentos da experiência. Entre a experiência de hoje e o juizo perceptivo da experiência de ontem, registra-se uma tensão entre ações no tempo, uma tensão entre o presente e o passado.*

Ontem e hoje se espelham mutuamente e permite à experiência de hoje se identificar no passado, porque lá encontra um padrão, um signo melhor elaborado dela mesma: uma aprendizagem que decorre da experiência sedimentada no repertório visto, então, como memória da experiência, uma aprendizagem que se equilibra entre a secundidade da ação, o sentimento dessa ação e a terceiridade alcançada pela inteligibilidade da experiência capaz de gerar um padrão de conduta, um hábito decorrente de ações e reações sedimentadas.

"O hábito conjugado com a motivação e as condições tem a ação com seu interpretante energético; mas a ação não pode ser um interpretante lógico pois lhe falta generalidade. O conceito que é interpretante lógico é ainda imperfeito. Partilha da natureza da

* Embora sob outro enfoque, Ibri (2) já estuda a questão o tempo no âmbito da terceiridade. 
definição verbal e como tal é inferior ao hábito, na mesma medida em que a definição verbal é inferior à definição real. O hábito deliberadamente constituído, auto-analisado auto-analisado porque foi formado com a ajuda da análise dos exercícios e por ela alimentado - é a definição viva, o verdadeiro e derradeiro interpretante lógico" (3. CP.5.491 - tradução colhida em 4.p. 154).

De certa forma, um repertório é a inteligibilidade da ação através do hábito, mas não é propriamente uma norma ou lei inferida de modo dedutivo, lógico e controlado. É o conjunto de sentimentos provocados pelo passado que substitui ou representa aquela experiência e influencia decisivamente nossas reações presentes. Os hábitos de um repertório cultural e informacional contém, à maneira dos juízos perceptivos, certa generalidade dedutiva, certa terceiridade, embora degenerada:

"A categoria de terceiridade exibe duas diferentes maneiras de degenerescência, onde a irredutível idéia de pluralidade distingüindo-se da dualidade está realmente presente, mas em condições mutiladas. O primeiro grau de degenerescência encontra-se em uma pluralidade irracional que, existindo em contradição à forma de sua representação, é uma mera complicação da dualidade. Temos um preciso exemplo disto na idéia de subdivisão. Como pura secundidade, os correlatos em reação são singulares e, como tais, individuais, não capazes de uma outra divisão. Consequientemente, a concepção de subdivisão, dizendo-se repetida dicotomia, certamente envolve uma espécie de terceiridade, mas é uma terceiridade concebida como consistindo em uma segunda secundidade. A terceiridade mais degenerada é aquela que concebemos como simples qualidade de sentimento ou primeiridade, representando-se a si mesma como representação. (3. CP.5.70, 71).

Essa terceiridade tem sua corrosão apoiada em certa singularidade do plural, certa particularidade geral que permite apreender, num interpretante lógico, sua raiz energética, no coletivo, os alicerces do indivíduo ou, no hábito, seus eventuais desvios possíveis, em outras palavras, vislumbrar, no geral, o fantasma da experiência que poderá desestruturá-lo.

Entretanto, é o repertório informacional que nos permite ver/interpretar a experiência e encontrar, no diagrama dos nossos juízos perceptivos, uma possibilidade de representação indutiva da experiência ou das hipóteses abdutivas apenas prováveis:

"O signo-pensamento representa o objeto na perspectiva por que o pensa; esta "perspectiva" é o objeto imediato da consciência no pensamento, ou o próprio pensamento, ou, pelo menos, o pensamento pensando no pensamento subsequiente a quem serve de signo" (3. CP.5.286 - tradução colhida em 4.p.80).

É da informação armazenada no repertório que depende a associação de idéias que nos leva à estratégia da pesquisa, responsável por aquela associação inusitada que conduz à descoberta do novo, à criatividade indutiva, outra forma de entender a questão da metodologia em ciência. Se sob a surpresa abdutiva, a indução deixa de ser simples comprovação de teorias, sob o impacto repertorial, a indução pode ser um momento de descoberta da experiência que nos envolve no quotidiano. É nessa estratégia criativa que se registra a passagem da abdução para a dedução, através do teste experimental indutivo, é na estratégia de pesquisa que a hipótese explicativa, abdutiva, possível, transformase em, não apenas, provável, mas necessária: da primeiridade para a terceiridade através da secundidade, da abdução para a dedução através da indução, da experiência para a lei através da experimentação. Sob o impacto da abdução, muda-se a compreensão tradicional do que se entende por dedução e indução, ou seja, se é da natureza da abdução produzir idéias, cabe às outras duas uma co-participação nessa tarefa, visto que à indução cabe evidenciar a validade dessa idéia e, à dedução, justificar, não só a relevância mas, sobretudo, pela generalização, avaliar o seu potencial enquanto idéia que propõe uma leitura inusitada da experiência: à dedução cabe identificar uma descoberta.

A ciência da experiência é aquela do olhar atento: o exercício científico como desenvolvimento de uma capacidade do homem: olhar para ver. Tenacidade ou sagacidade? Sem reduzir a questão a uma simplicidade dicotômica e salvando a indispensável dialéti-

Trans/Form/Ação, São Paulo, 9/10: 1-7, 1986/87. 
ca entre aqueles pólos, a predominância de um ou outro aspecto caracteriza a natureza do que se convencionou chamar produção científica. Ciência para acumular conhecimentos ou para produzir o novo. Uma questão de olhar.

\section{NOTAS}

Peirce preocupou-se em estudar as categorias da experiência e, para isso, criou e desenvolveu uma Ideocospia de caráter numérico e distinta das classificações fenomenológicas.

Todos os elementos da experiência pertencem a três classes, denominadas categorias cenopitagóricas, a saber:

Primeiro, experiências monádicas ou simples, em que os elementos são de tal natureza que poderiam ser o que são sem inconsistência, ainda que nada mais houvesse na experiência.

Segundo, experiências diádicas ou recorrências onde cada uma é uma experiência direta de um par de objetos em exposição.

Terceiro, experiências triádicas ou compreensão onde cada uma é uma experiência direta em conexão com outras experiências possiveis (3. C.P. 7.528).

Experiência monádica ou de primeiridade é a experiência de uma qualidade; experiência diádica ou de secundidade é aquela proporcionada pela reação a um choque, a um conflito entre ações ou hábitos, ocorrendo aqui, agora e apenas uma vez, se repetida e contínua, passa a ser reação com força de lei e, aí, estamos no domínio da experiência triádica ou de terceiridade.

D'ALÉSSIO FERRARA, L. - Science of the attentive eye. Trans/Form/Ação, São Paulo, 9/10: 1-7, $1986 / 87$.

ABSTRACT: What is science? What is the distinction between scientific knowledge and living science, science of experience. Peirce's pragmatism. The scientific dimension of Peirce's categories: deduction, abduction, induction. Induction as a connection between the abductive hypothesis, that is only probable and the generation of a deductive and indispensable law that characterises behavior habits.

KEY-WORDS: Science; scientific knowledge; induction; deduction; abduction; experience; law; experiment

\section{REFERÊNCIAS BIBLIOGRÁFICAS}

1. GRAMSCI, A. - Obras escolhidas. São Paulo, Martins Fontes, 1978.

2. IBRI, I. A. - Kósmos Noetós, arquitetura metaffsica de Charles Sanders Peirce. São Paulo, PUC, 1986. (Dissertação de Mestrado).

3. PEIRCE, C. S. - Collected Papers. Cambridge, Harvard Press, 1944. 4 v.

4. PEIRCE, C. S. -Papéis Coligidos. São Paulo, Abril, 1978. (Coleção Pensadores). 


\section{BIBLIOGRAFIA CONSULTADA}

BUCZYNSKA-GAREWICZ, H. - The interpretant and a System of Signs. Ars Semiotica, 4(2):187-200, 1982.

BUCZYNSKA-GAREWICZ, H. - Sign and Dialogue. American Journal of Semiotics, 2(1/2):27-43, 1983.

ECO, U. - Guessing: from A ristotle to Sherlock Holmes. VIS, 30:3-19, s.d.

KOLENDA, K. - Truth and Fallibilism. Transactions of the Charles Sanders Peirce Society, 15(3):251-258, 1979.

KUHN, T. - A estrutura das revoluçōes cientfficas. São Paulo, Perspectiva, 1975. (Coleção Debates).

PRONI, G. - Genesi e senso dell'abduzione in Peirce. V/S, 28:29-50, s.d.

ROSENTHAL, S. - Peirce's theory of the percentual judgments: an ambiguity. Journal for the History of Philosophy, 7:303-314, 1969.

SILVEIRA, L. F. B. - Um estudo semiótico da estratégia burguesa de determinação da conduta social." Ciência e Cultura, 36(3):377-385, 1984.

SINI, C. - Abduzione e cosmologia in Peirce. V/S, 34:13-20, 1983. 